\title{
The Impact of Quality Cost on Financial Performance of Banks Operating in Jordan
}

\author{
Dr. Maher Diab Abulaila* \\ Assistant Professor in Accounting \\ Imam Abdulrahman \\ Bin Faisal University-Accounting Department \\ College of Applied Studies \& Community Service, Saudi Arabia \\ Abeer Atallah Aloudat \\ Lecture in Accounting \\ Imam Abdulrahman \\ Bin Faisal University-Accounting Department \\ College of Applied Studies \& Community Service, Saudi Arabia
}

\begin{abstract}
This study aimed at examining the impact of quality cost on the financial performance of banks operating in Jordan. The population of the study consisted of the (25) banks operating in Jordan, while the sample included (12) banks for which all needed data for the period (2009-2015) were available. These banks formed (48\%) of the population. To achieve its objectives, the study employed the analytical descriptive approach, where data on the variables of the study were obtained from the sample banks' annual financial reports. The independent variable of the study (quality cost) was measured by preventive costs, appraisal costs, internal failure costs, and external failure costs. While the dependent variable (performance) was measured by three financial indicators (return on assets, earnings per share and Tobin Q). In addition, the control variable (bank size) was measured by the total assets of the bank. A number of statistical techniques were used in analyzing the data, such as, (means, standard deviations, multiple regression, Hausman Test). E views statistical program was used to analyze the data.The study reached to a number of results, the most important of which is that banks operating in Jordan are concerned about quality activities. In general, the results indicated the existence of a statistically significant effect of quality cost on financial performance. The study also indicated that there are variations in the effect of the quality costs dimensions (negative and positives) on the financial performance indicators. Furthermore, the results indicated that the size of the bank is the most important variable in affecting the performance of banks operating in Jordan. The study concluded with a number of recommendations, the most important of which is that banks must give attention to appraisal costs because the results of the study indicated that there is a positive effect of these costs on the returns of assets and on Tobin Q. The study also recommended that banks must improve the effectiveness of their strategic decisions taken towards the use of their assets in generating profits through increasing their investments. In addition, there is a necessity of increasing the investment in the preventive costs because they have an important role in reducing the internal failure costs and the external failure costs that result from not complying with the quality requirement.
\end{abstract}

Keywords: Quality costs, Preventive costs, Appraisal costs, Internal failure costs, External failure costs, Financial performance, Banks operating in Jordan.

DOI: $10.7176 /$ RJFA/10-2-06

\section{Introduction}

Business organizations in general and organizations working in the banking sector in particular seek to achieve the competitive advantages that enable them to face the serious challenges of global competition, to ensure survival and continuity, and to seek ways and means to help them achieve such advantages.

Interest in quality cost is one of the important and modern methods that will lead to cost reduction, improve quality and its positive impact on performance which lead the efforts of the management of banks operating in Jordan to the cost of quality in its four dimensions (prevention, evaluation, internal failure, and external failure). And to monitor the performance of Jordanian commercial banks in order to achieve their vision, mission, and strategic objectives, thus affecting the banking activity and the growth and prosperity of the national economy. So, this study was to discuss the impact of quality cost on the financial performance of banks operating in Jordan.

\section{The Importance of the Study}

The importance of this study stems from the importance of quality costs in enhancing the competitive position of banks, increasing the efficiency of their operations, reducing costs, improving profits and thus increasing the quality of service provided to customers and improving their performance to achieve competitive advantage. So, the importance of this study summarized in the following points: 
1. Studying the cost of quality and its components to provide information to the bank's management to assist it in carrying out its various functions of planning, control, and decision-making to achieve the objectives.

2. Attention and focus on elements of quality costs and increase investment in elements that are important in achieving competitive advantage.

3. Attention to quality costs and their components lead to less time to perform and accomplish the tasks with lower costs and thus decrease the complaint of the beneficiaries of these services and increase their satisfaction.

\section{Objectives of the Study}

The objectives of the study are to identify the impact of quality costs on improving the financial performance of Jordanian banks by achieving the following objectives:

1. Study the impact of quality costs in light of the existence of the variable (the size of the bank) on the rate of return on assets in banks operating in Jordan.

2. Study the impact of quality costs in light of the existence of the variable (the size of the bank) on the earnings per share in the banks operating in Jordan.

3. Study the impact of quality costs in light of the existence of the variable (size of the bank) on the value of Tobin's Q ratio in banks operating in Jordan.

\section{The Study Problem:}

This study presents other options for banks to improve their financial performance by demonstrating the impact of quality costs in their four dimensions (prevention, assessment, internal failure, and external failure) on improving the financial performance of banks operating in Jordan.

In view of the above, the problem of the study is crystallized in the following questions:

1. Does the quality costs in the presence of the variable the size of the bank affect the rate of return on assets in banks operating in Jordan?

It has the following sub-questions:

A. Does the prevention costs affect the rate of return on assets in banks operating in Jordan?

B. Does the evaluation costs affect the rate of return on assets in banks operating in Jordan?

C. Does the internal failure costs affect the rate of return on assets in banks operating in Jordan?

D. Does the external failure costs affect the rate of return on assets in banks operating in Jordan?

E. Does the size of the bank affect the rate of return on assets in banks operating in Jordan?

2. Does the quality costs in the presence of the variable the size of the bank affect on the earning per share rate in banks operating in Jordan?

It has the following sub-questions:

A. Does the prevention costs affect the earning per share rate in banks operating in Jordan?

B. Does the evaluation costs affect the earning per share rate in banks operating in Jordan?

C. Does the internal failure costs affect the earning per share rate in banks operating in Jordan?

Dr. Does the external failure costs affect the earning per share rate in banks operating in Jordan?

E. Does the size of the bank affect the earning per share rate in banks operating in Jordan?

3. Does the quality costs in the presence of the variable the size of the bank affect on the value of Tobin's Q ratio in banks operating in Jordan?

It has the following sub-questions:

A. Does the prevention costs affect the value of Tobin's Q ratio in banks operating in Jordan?

B. Does the evaluation costs affect the value of Tobin's Q ratio in banks operating in Jordan?

C. Does the internal failure costs affect the value of Tobin's Q ratio in banks operating in Jordan?

Dr. Does the external failure costs affect the value of Tobin's Q ratio in banks operating in Jordan?

E. Does the size of the bank affect the value of Tobin's Q ratio in banks operating in Jordan?

Relationship of Quality Costs to Financial Performance

The improvement of financial performance depends on providing the best services and reducing the cost of operations. The most important determinants facing the company's outstanding financial performance is its ability to achieve competitive advantages by providing its services at the lowest possible cost, taking into account the quality component. Accordingly, the financial performance of companies is affected by the following factors: Competition, market, economic factors, external dimensions of the environment, quality factors, distinctive capabilities, operational processes, competitive advantage, as factors that include and act on the basis of the internal environment, According to Horngren et al. (2012), based on the measures of accounting for the cost of quality and its basis in capital investment decisions, they shows that there is a relationship between the measuring quality costs and financial performance measurements. This is illustrated as follows:

The financial measurement of quality costs seeks to improve quality and prioritize cost reduction.

Quality costs pay attention to poor quality because it is one of the highest quality costs.

The basis of the assessment of the state of balance between prevention costs and failure costs is measurement. 
Quality and measurement costs contribute to the knowledge of costs that significantly affect the reduction or increase of the total cost of quality and treatment, which reduces total costs and the consequent improvement and development of performance. (Feigenbaum, 1991) develop a set of indicators to measure the cost of quality and its relationship to the activities and other elements of the company. These indicators are used to explain the ratio of quality costs to the approved basis as follows:

.Manufacturing costs $=$ Total cost of quality $/$ Total cost of manufacturing $\times 100$

Sales Indicators $=$ Total cost of quality / Sales value $\mathrm{x} 100$

Based on the above, the measurement of quality costs requires a clear knowledge of the concept of basic quality costs and their sub-components.

Slack et al. (1998) points to the relationship between high-quality level, costs, and profits. The high-quality leads to the improvement of the quality of products and services, which increases the volume of sales and leads to the improvement of the economic standards of the company and thus reduce the prices paid.

The measurement and analysis of the cost of quality lead to positive results, where there are many factors that give the company a competitive advantage in the market position, which increases the company's share in the market and the high proportion of sales and reputation and confidence of customers. All this represents a positive investment for the long-term and confirms the relationship between the quality of products produced by the company and financial performance. (Slack et al., 1998) indicates that high quality entails higher productivity and lower costs. There are many elements that aim to reduce the cost of quality (such as salvage value, inspection, testing, complaints, guarantee, and re-employment) Among the areas affected are: (low competitive prices, high productivity, new image of the company and high volume of sales), which is reflected in revenues, leading to an increase in profitability and its impact on financial performance in general.

Jassim (2008) noted that there is a relationship between quality improvement and competitive position, customer satisfaction, and profitability. Quality improvement will lead to improve resources exploitation efficiency and improved productivity, increase customer satisfaction and higher market share that leads to higher returns.

\section{Previous Studies}

Akenbor, 2014, "An Accounting Reflection of Quality Cost and Customer Satisfaction of Health Products in Nigeria"

The objective of this study was to identify the reflection of the accounting costs of quality control and customer satisfaction on health products in Nigeria. To achieve the objectives of the study, the descriptive analytical method was used. A questionnaire was developed and distributed to the selected sample of (7) accountants in medicines companies listed in Nigerian stock exchange. Relying on statistical analysis using One Sample T-test and regression analysis in the hypothesis test. The results of the study revealed that there is a positive relationship between the cost of quality and the costs of conformity and customer satisfaction of health products and recommended the study of the need to pay attention to quality and methods of measurement.

Trehan et al., 2014, "Cost of Quality-A System Dynamics Approach"

The objective of this study was to identify the impact of quality costs on investment in preventive activities as well as to identify the impact of quality costs on return on investment and change in the total cost of quality over a period of time. This impact on the management's understanding of the costs of preventive activities and failure costs. The causal diagram as a dynamic tool to determine the relationship between variables, and to analyze the impact of the change in cost factors on a given scale and time and found that the costs of preventive activities are most influential on return on investment.

Al-Dujaili, 2013 "Study of the Relation between Types of the Quality Costs and its Impact on Productivity and Costs: A Verification in Manufacturing Industries"

The objective of this study was to verify the relation between quality control (QC) and quality costs as they are essential elements for the survival of organizations in the market, where the study focused on measuring the cost of quality in terms of (prevention, evaluation, internal failure, external failure), and to identify the nature of the relationship between the types of quality and total cost of quality costs. As well as to measure the impact of quality improvement in productivity, thus creating a practical opportunity to make improvements to the organization. The study based on a data collected from records of fabric companies in Iraq, and after statistical analysis using the test (One-Sample T-test) and regression analysis the results showed that technological obsolescence leads to an increase in the proportion of products defective, thereby increasing costs, lower quality, and productivity levels.

Methodology and procedures

\section{The study population}

The study population consists of all 25 banks operating in Jordan according to the annual report of the Central Bank of Jordan for the year 2016 
Statistical analysis and hypothesis testing: To test the hypothesis, multiple linear regression was used within the random effects model, and the variable (bank asset size) was introduced as an independent variable in the model. The first main hypothesis

H01: There is no statistically significant effect at $(\alpha \leq 0.05)$ for quality costs in presence of the existence of the variable (bank size) on the rate of return on assets in banks operating in Jordan.

Table (1) Multiple regression results of the first main hypothesis

\begin{tabular}{|l|l||l||l|l||}
\hline \multicolumn{2}{|l||l||}{ Rependent Variable: Return on Assets ROA } & Random Effect \\
\hline \hline Variables & B & St. Error & T. Test & P- Value \\
\hline \hline C & -6.912864 & 2.134083 & -3.239267 & 0.0018 \\
\hline \hline Prevention Costs & -0.177669 & 0.232950 & -0.762693 & 0.4482 \\
\hline \hline Evaluation Costs & 0.369256 & 0.121583 & 2.199395 & $0.0308^{*}$ \\
\hline \hline Internal Failure Costs & -0.219075 & 0.195135 & -1.122686 & 0.2654 \\
\hline \hline External Failure Costs & -0.100917 & 0.077204 & -1.307144 & 0.1954 \\
\hline \hline Bank Size & 0.604348 & 0.191178 & 3.161179 & 0.0003 \\
\hline \hline R2 & $33.17 \%$ & D.W test & & 2.18 \\
\hline \hline F. Test & 7.05 & Probability F & 0.0000 \\
\hline
\end{tabular}

Table (1) shows that the value of Durbin-Watson has indicated that there is no autocorrelation between errors in the regression equation (2.18), which is within the accepted limits of this test.

Accordingly, the results of the F test indicate rejection of the null hypothesis H01 and acceptance of alternative hypothesis $\mathrm{H} 1$, that "there is a statistically significant effect at the level of $(\alpha \leq 0.05)$ of the quality costs in the presence of the variable (company size) on the rate of return on assets In banks operating in Jordan " Because the value of $\mathrm{F}$ calculated was (7.05), which is significant at the level of significance of $5 \%$, where the probability value of $\mathrm{F}(0.0000)$, which is less than $5 \%$ and indicate the quality of conciliation model. And the effect of independent variables the quality costs in the presence of the size of the assets of the bank has an explanatory power acceptable to the dependent variable. The value of the interpretation factor R2 was $(33.17 \%)$ which means that it interprets $33.17 \%$ of the change in the return on Assets with remaining other factors constant, which meaning that there are other factors affecting the return on assets not taken into the model.

\subsection{The sub-hypothesis was tested, and the results were as follows:}

First sub-Hypothesis H01-1: There is no statistically significant effect at the level $(\alpha \leq 0.05)$ for the prevention costs on the rate of return on assets in banks operating in Jordan.

The results of the table (1) indicate that the value of the B coefficient of prevention costs reached (- 0.177) and the standard error (0.2329), and the calculated value of $t(-0.7626)$. It indicates the inverse relationship between the prevention costs and the return on assets at a Sig $=(0.4482)$, which confirms the absence of a significant effect of the cost of prevention on the rate of return on assets at the level of $(\alpha \leq 0.05)$.

Accordingly, we accept the null hypothesis which states that "there is no statistically significant effect of the prevention costs on the rate of return on assets in banks operating in Jordan".

Second Sub-Hypothesis H01-2: There is no statistically significant effect at the level $(\alpha \leq 0.05)$ for the evaluation costs on the rate of return on assets in banks operating in Jordan.

The results of the table (1) indicate that the value of the B coefficient for the evaluation costs reached (0.3692), the standard error (0.1215) and the calculated value of $t$ (2.1993) which indicate a positive relationship between the evaluation costs and the return on assets at a Sig $=(0.0308)$, Which confirms the significant effect of the evaluation costs on the rate of return on assets at the level.

Accordingly, we reject the null hypothesis and accept the alternative, which states that "there is a statistically significant impact of the evaluation costs on the rate of return on assets in banks operating in Jordan."

The Jordanian banks are influenced by their performance in this type of cost, as they are highly concerned with the costs allocated for auditing, controlling, and measuring the quality of service in order to meet the quality standards and meet the needs of the customers, in order to avoid errors before providing the service to the customer, which is reflected positively on the rate of return on assets achieved by the bank.

Third Sub-Hypothesis H01-3: There is no statistically significant effect at the level $(\alpha \leq 0.05)$ for internal failure costs on the rate of return on assets in banks operating in Jordan.

The results of the table (1) indicate that the value of the B coefficient for internal failure costs reached ($0.2190)$ and the standard error $(0.1951)$, and the calculated t value (-1.1126), indicates an inverse relationship between internal failure costs and the rate of return on assets at $(\mathrm{Sig}=0.2654)$, which confirms that there is no significant effect of the internal failure costs on the rate of return on assets.

Accordingly, we accept the null hypothesis which states that "there is no statistically significant effect on 
the internal failure costs on the rate of return on assets in banks operating in Jordan."

Forth Sub-Hypothesis H01-4: There is no statistically significant effect at the level $(\alpha \leq 0.05)$ for the external failure costs on the rate of return on assets in banks operating in Jordan.

The results of the table (1) indicate that the value of the B coefficient for the external failure costs reached $(-0.1009)$ and the standard error $(0.0772)$ and the calculated t value $(-1.3071)$. It indicates an inverse relationship between the external failure costs and the return on assets at ( $\mathrm{Sig}=0.1954)$, which confirms that there is no significant effect of the external failure costs on the rate of return on assets.

Accordingly, we accept the null hypothesis which states that "there is no statistically significant effect of external failure costs on the rate of return on assets in banks operating in Jordan".

Fifth Sub-Hypothesis H01-5: There is no statistically significant effect at the level $(\alpha \leq 0.05)$ of the size of the bank on the rate of return on assets in banks operating in Jordan.

The results of the table (1) show that the value of the Bank Size B coefficient was (0.6043) and the standard error $(0.1911)$. The calculated $t$ value $(3.1611)$ which indicates the positive relationship between the size of the bank and the return on assets at a significant level $(\mathrm{Sig}=0.0003)$, Which confirms the existence of a significant effect of the size of the bank on the rate of return on assets at the level.

Accordingly, we reject the null hypothesis and accept the alternative, which states that "there is a statistically significant effect on the size of the bank on the rate of return on assets in banks operating in Jordan."

The size of the bank is considered to be an indicator of the bank's market share in the market. The increase in the size of the bank may mean an increase in individual deposits and thus an increase in the bank's ability to grant customer loan facilities, which increases the bank's revenue, thus reflects positively on its profitability and performance indicators.

\subsection{The second main hypothesis}

H02: There is no statistically significant effect at the level $(\alpha \leq 0.05)$ for quality costs in presence of the existence of the variable (bank size) on the earning per share rate in banks operating in Jordan.

Table (2) Multiple regression results of the second main hypothesis

\begin{tabular}{|l|l||l||l||l|}
\hline \multicolumn{2}{|l||}{ Dependent Variable: Earning per share EPS } & Random Effect & \multicolumn{2}{l|}{$\mid$} \\
\hline \hline Variables & B & St. Error & T. Test & P- Value \\
\hline \hline C & -2.726873 & 0.343281 & -7.943553 & 0.0000 \\
\hline \hline Prevention Costs & -0.006601 & 0.037471 & -0.176156 & 0.8607 \\
\hline \hline Evaluation Costs & -0.106368 & 0.019557 & -2.199395 & 0.0308 \\
\hline \hline Internal Failure Costs & -0.017467 & 0.031389 & -0.556486 & 0.5796 \\
\hline \hline External Failure Costs & -0.092983 & 0.030419 & -2.050631 & 0.0384 \\
\hline \hline Bank Size & 0.172832 & 0.030752 & 5.620139 & 0.0000 \\
\hline \hline R2 & $62.68 \%$ & D.W test & & 1.84 \\
\hline \hline F. Test & 23.85 & Probability F & & 0.0000 \\
\hline
\end{tabular}

Table (2) shows that the value of Durbin-Watson has indicated that there is no autocorrelation between errors in the regression equation (1.84), which is within the acceptable limits of this test.

Accordingly, the results of the $\mathrm{F}$ test indicate rejection of the null hypothesis and acceptance of the alternative hypothesis which states that "there is a statistically significant effect at the level $(\alpha \leq 0.05)$ of the quality costs in the presence of the variable (bank size) on the earning per share rate in banks operating in Jordan. " Because the value of $\mathrm{F}$ calculated at (23.85), which is significant at the level of significance of $5 \%$, where the probability value of $F(0.0000)$, which is less than $5 \%$, indicating the quality of conciliation model. The effect of the independent variables quality costs combined in the presence of the variable bank size has an explanatory power acceptable to the dependent variable EPS, where the value of the interpretation factor is $(62.68 \% \mathrm{R} 2)$, it accounted for $62.68 \%$ of the change in EPS with other factors is fixed, meaning that there are other factors affecting the EPS not taken into the model.

The researchers believe that the banks interest in improving quality leads to retaining existing customers and attracting new customers, and even the acquisition of some customers who want to change and benefit from what is developed from competitors and thus increase the bank's market share and increase the profits of the bank, which reflect positively on the earning per share of these profit.

The sub-hypothesis was tested, and the results were as follows:

First Sub-Hypothesis H02-1: There is no statistically significant effect at the level $(\alpha \leq 0.05)$ for the prevention costs on the earning per share rate in banks operating in Jordan.

The results of the table (2) indicate that the value of the B coefficient of prevention costs reached (0.0066-) and the standard error (0.0374), and the calculated $t$ value (0.1761-) and the inverse relationship between prevention costs and EPS at $(\mathrm{Sig}=0.8607)$, which confirms that there is no significant effect of the prevention costs on the 
earning per share rate at the level $(\alpha \leq 0.05)$.

Accordingly, we accept the null hypothesis which states that "there is no statistically significant effect of the prevention costs on the earning per share rate in banks operating in Jordan".

Second Sub-Hypothesis H02-2: There is no statistically significant effect at the level $(\alpha \leq 0.05)$ for the evaluation costs on the earning per share rate in banks operating in Jordan.

The results of the table (2) indicate that the value of the B coefficient for the evaluation costs reached (0.1063-) and the standard error (0.0195). The calculated value of $t(-2.1993)$, which indicates the inverse relationship between the evaluation costs and the EPS at ( $\mathrm{Sig}=0.0308)$, which confirms the significant effect of the evaluation costs on the EPS at $(\alpha \leq 0.05)$.

Accordingly, we reject the null hypothesis and accept the alternative hypothesis, which states that "there is a statistically significant effect of the evaluation costs on the earning per share rate in banks operating in Jordan."

Third Sub-Hypothesis H02-3: There is no statistically significant effect at the level $(\alpha \leq 0.05)$ for the internal failure costs on the earning per share rate in banks operating in Jordan.

The results of the table (2) show that the value of the B coefficient for internal failure costs reached $(-0.0174)$ and the standard error (0.0313). The calculated value of $\mathrm{t}(-0.5564)$ indicates the inverse relationship between the internal failure costs and the EPS at ( $\mathrm{Sig}=0.5796)$, which confirms that there is no significant effect of internal failure costs on the EPS at $(\alpha \leq 0.05)$.

Accordingly, we accept the null hypothesis which states that "there is no statistically significant effect of the internal failure costs on the earnings per share rate in banks operating in Jordan".

Forth Sub-Hypothesis H02-4: There is no statistically significant effect at the level $(\alpha \leq 0.05)$ for the external failure costs on the earnings per share rate in banks operating in Jordan.

The results of the table (2) indicate that the value of the B coefficient for external failure costs was $(-0.0929)$ and the standard error (0.0304). The calculated value of $\mathrm{t}(-2.0506)$ was the inverse relationship between the external failure costs and the EPS at $(\mathrm{Sig}=0.0384)$, which confirms that there is a significant effect of external failure costs on the EPS at $(\alpha \leq 0.05)$.

Accordingly, we reject the null hypothesis and accept the alternative, which states that "there is a statistically significant effect of external failure costs on the earning per share rate in banks operating in Jordan".

The researchers believe that decreasing external failure costs in banks affects banks earnings positively, which is directly related to customers and the providing of services in a distinctive and high quality manner, which contributes to keeping abreast of the changes taking place in the banking environment at the lowest possible cost, enhancing the confidence of existing customers and attracting new customers, which in turn positively affects the profitability of the bank and thus increasing the earning per share rate.

Fifth Sub-Hypothesis H02-5: There is no statistically significant effect at the level $(\alpha \leq 0.05)$ of the size of the bank on the earning per share rate in banks operating in Jordan.

The results of the table (2) indicate that the value of the Bank's size B coefficient was $(0.1728)$ and the standard error (0.0307). The calculated value of $\mathrm{t}$ (5.6201) and refers to a positive relationship between the size of the bank and the EPS at ( $\operatorname{Sig}=0.0000)$, Which confirms the existence of a significant effect of the size of the bank on the earning per share rate at the level $(\alpha \leq 0.05)$.

Accordingly, we reject the null hypothesis and accept the alternative hypothesis, which states that "there is a statistically significant effect on the size of the bank on the earning per share rate in banks operating in Jordan."

\subsection{The Third Main hypothesis}

H03: There is no statistically significant effect at $\alpha(\alpha \leq 0.05)$ for quality costs in the presence of the variable (bank size) on the value of Tobin's Q ratio in banks operating in Jordan.

Table (3) Multiple regression results of the third main hypothesis

\begin{tabular}{|l||l||l||l||l||}
\hline Dependent Variable: Tobin's Q Ratio & Method: Fixed Effect \\
\hline \hline Variables & B & St. Error & T. Test & P- Value \\
\hline \hline C & 4.200863 & 0.587651 & 7.148566 & 0.0000 \\
\hline \hline Prevention Costs & 0.042682 & 0.034102 & 1.251616 & 0.2155 \\
\hline \hline Evaluation Costs & 0.103195 & 0.037325 & 2.103616 & 0.0347 \\
\hline \hline Internal Failure Costs & -0.110257 & 0.044289 & -2.489487 & $0.0155^{*}$ \\
\hline \hline External Failure Costs & -0.019325 & 0.015064 & -1.282819 & 0.2044 \\
\hline \hline Bank Size & 0.197026 & 0.034181 & 5.764152 & 0.0000 \\
\hline \hline R2 & $69.40 \%$ & D.W test & & 1.802 \\
\hline \hline F. Test & 09.22 & Probability F & 0.0000 \\
\hline
\end{tabular}

Table (3) shows that the value of Durbin-Watson has indicated that there is no autocorrelation between errors in the regression equation (1.802), which is within the acceptable limits of this test. 
Accordingly, the results of the $\mathrm{F}$ test indicate rejection of the null hypothesis and acceptance of the alternative hypothesis that states "there is a statistically significant effect at the level of $(\alpha \leq 0.05)$ of the quality costs in the presence of the adjustable variable (bank size) on the value of Tobin's Q ratio in banks operating in Jordan ". Because the calculated value of $\mathrm{F}$ has reached (9.22), which is significant at the level of significance of $5 \%$, where the probability value of $\mathrm{F}(0.0000)$ is less than $5 \%$, indicating the quality of conciliation model. And the effect of independent variables quality costs combined in the presence of the variable bank size has an explanatory power acceptable to the dependent variable Tobin's Q ratio, where the interpretation factor was (R2 $=69.40 \%$ ), of the change in Tobin's $\mathrm{Q}$ ratio with other factors remaining constant, meaning that other factors affecting Tobin's Q ratio were not taken into the model.

\subsection{The sub-hypothesis was tested, and the results were as follows:}

6.4.1 The First Sub-Hypothesis H03-1: There is no statistically significant effect at $(\alpha \leq 0.05)$ for the prevention costs on Tobin's Q ratio in banks operating in Jordan.

The results of the table (3) indicate that the value of the B coefficient of prevention costs reached $(0.0426)$, the standard error (0.0341) and the calculated value of $t$ (1.2516), which indicate a positive relationship between the prevention costs and Tobin's Q ratio at $(\mathrm{Sig}=0.2155)$, Which confirms that there is no significant effect of the prevention costs on Tobin's $Q$ ratio at the level $(\alpha \leq 0.05)$.

Accordingly, we accept the null hypothesis that "there is no statistically significant effect of the prevention costs on Tobin's Q ratio in banks operating in Jordan."

Second Sub-Hypothesis H03-2: There is no statistically significant effect at $(\alpha \leq 0.05)$ for the evaluation costs on Tobin's Q ratio in banks operating in Jordan.

The results of the table (3) indicate that the value of the $\mathrm{B}$ coefficient for the evaluation costs reached (0.1031), the standard error (0.0373) and the calculated value of $t$ was (2.1036), which indicate a positive relationship between the evaluation costs and Tobin's $Q$ ratio at $(\mathrm{Sig}=0.0347)$, which confirm a significant effect of the evaluation costs on Tobin's $Q$ ratio at $(\alpha \leq 0.05)$.

Accordingly, we reject the null hypothesis and accept the alternative hypothesis, which states that "there is a statistically significant effect of the evaluation costs on Tobin's Q ratio in banks operating in Jordan."

The researchers believe that banks interest in the evaluation cost, which related to the maintenance of modern systems and programs, audit fees, and meet the needs of customers to avoid the provision of nonconforming services reflected positively on the reputation of the bank and thus better increase demand on the bank share, and thus an increase in the Tobin's Q Index for the bank share

Third Sub-Hypothesis H03-3: There is no statistically significant effect at $(\alpha \leq 0.05)$ for internal failure costs on

\section{Tobin's Q ratio in banks operating in Jordan.}

The results of the table (3) indicate that the value of the B coefficient for internal failure costs reached $(-0.1102)$, the standard error $(0.0442)$, and the calculated $t$ value $(-2.4894)$. It indicates the inverse relationship between internal failure costs and Tobin's $Q$ ratio at $(\mathrm{Sig}=0.0155)$, which confirm a significant effect of internal failure costs on Tobin's $Q$ ratio at $(\alpha \leq 0.05)$.

Accordingly, we reject the null hypothesis and accept the alternative hypothesis, which states that "there is a statistically significant effect of the internal failure costs on Tobin's Q ratio in banks operating in Jordan."

The researchers believe that the low costs of internal failure at the bank reflected positively on the reputation of the bank in the financial market, which reflected on the share price rise and leads to the increase Tobin's Q ratio of the bank.

Forth Sub-Hypothesis H03-4: There is no statistically significant effect at $(\alpha \leq 0.05)$ for the external failure costs on Tobin's Q ratio in banks operating in Jordan.

The results of the table (3) indicate that the value of the B coefficient for external failure costs was ($0.0193)$, the standard error $(0.0150)$ and the calculated value of $t(-1.2828)$, which indicates the inverse relationship between external failure costs and Tobin's Q ratio at ( $\mathrm{Sig}=0.2044)$, which confirms that there is no significant effect of external failure costs on Tobin's Q ratio at $(\alpha \leq 0.05)$.

Accordingly, we accept the null hypothesis which states that "there is no statistically significant effect for external failure costs on Tobin's Q ratio in banks operating in Jordan."

Fifth Sub-Hypothesis H03-5: There is no statistically significant effect at $(\alpha \leq 0.05)$ of the size of the bank on Tobin's Q ratio in banks operating in Jordan.

The results of the table (3) indicate that the value of the B coefficient for the size of the bank reached (0.1970), the standard error (0.0341) and the calculated value of $t$ (5.7641), which indicates a positive relationship between the size of the bank and Tobin's Q ratio at ( $\mathrm{Sig}=0.0000)$, which confirms the existence of a significant effect of the size of the bank on Tobin's Q ratio at $(\alpha \leq 0.05)$.

Accordingly, we reject the null hypothesis and accept the alternative hypothesis, which states that "there is a 
statistically significant effect on the size of the bank on Tobin's Q ratio in banks operating in Jordan."

The researchers believe that the increase in the size of the bank will increase the customers withdrawal, deposit, and remittances, and will lead to an increase in the volume of deposits as well as the volume of facilities, which will increase the profitability of the bank.

\section{Conclusions and Recommendations}

\subsection{Conclusions}

Based on the results of data analysis and hypothesis testing, the study reached the following conclusions:

1. Banks operating in Jordan are interested in quality activities operations. Compliance costs related to prevention costs and evaluation costs were averaged $(75.79 \%)$ of total quality costs during the study period between 2009 and 2015, reflecting the degree of interest of these banks in reaching the level of the quality required and maintained, and the reduction of losses and negative consequences resulting from lack of attention to quality.

2. Banks operating in Jordan spent less on internal and external failure costs. The internal and external failure costs were averaged (24.21\%) of total quality costs over the years 2009-2015, which can be considered as an indication on increase interest in using all their capabilities to maintain their reputation by focusing on customer satisfaction, meeting their needs by providing new services, attracting new customers, addressing the intense competition in the work environment, and regularity and consistency in the quality of services provided to customers and their development continuously.

3. There is a statistically significant effect on the quality costs in light of the existence of the variable (bank size) on the earning per share rate, so that the quality costs were interpreted in its four dimensions, with the size of the bank being $(62.68 \%)$ of the variance of the accounting measure the earning per share rate.

4. The existence of a statistically significant effect on the quality costs in the presence of the variable (bank size) on (Tobin's Q) ratio, so that the quality costs were interpreted in its four dimensions, with the size of the bank being $(69.40 \%)$ of the variance between the market value of Tobin's Q for banks operating in Jordan.

\subsection{Recommendations}

Based on the results of the study, the researchers recommend the following:

1. Banks should take care of the evaluation costs, such as auditing the quality of the service from all aspects administrative, financial, technical and banking data because they have a role in increasing the return on assets, where it was found to have a positive impact on improving the rate of return on assets and the value of Tobin's Q ratio.

2. Increasing investments from banks management in prevention costs. It has been shown that there is no significant effect of prevention costs on the financial performance of the banks because they have a role in reducing both internal and external failure costs.

3. The need for banks to take care of the quality costs in terms of measurement and disclosure in the financial statements because attention to quality costs and disclosure of elements is expected to lead to increasing the market share of the bank.

Appendix 1: The study variables and methods of measurement:

\begin{tabular}{|l||l||l||}
\hline Variables & Symbol & How to measure \\
\hline \hline Return on Assets & ROA & Net profit / Total Asset \\
\hline \hline Earnings Per Share & EPS & Net profit / number of ordinary sharesoutstanding and traded \\
\hline \hline Value Tobin's Q & Tobin's Q & The market value of the shares/ Book value of the shares \\
\hline \hline Prevention Costs & X1 & $\begin{array}{l}\text { Training costs }+ \text { travelcosts subscriptions and memberships }+ \\
\text { Advertising + Hospitality + Optical expenses + Insurance life of } \\
\text { employees }\end{array}$ \\
\hline \hline Evaluation Costs & $\begin{array}{l}\text { intenance softwareMa and systems + Maintenance and repairs }+ \\
\text { auditing fees }\end{array}$ \\
\hline \hline Failure Internal Costs & X2 & $\begin{array}{l}\text { Mail and phone + stationery and supplies }+ \text { baddebts }+ \text { Cost of } \\
\text { work injuries and compensation }\end{array}$ \\
\hline \hline Failure External Costs & Xudiciary andthe legal services costs + delay fees \\
\hline \hline Bank Size & X5 & Natural logarithm of the total assets of the bank \\
\hline
\end{tabular}

\section{References}

Akenbor, Cletus O. (2014). An Accounting Reflection of Quality Cost and Custome Satisfaction of Health Products in Nigeria. Journal of Business and Retail Management Research (JBRMR), 8 (2), P. 42.

Al-Dujaili, Mohammed A. Ahmed (2013). Study of the Relation between Types of the Quality Costs and its 
Impact on Productivity and Costs: Verification in Manufacturing Industries. Total, 24 (4), p. 397-419.

Dong, H. P. And Su, J. (2010). The Relationship between Working Capital Management and Profitability: A Vietnam Case International Research Journal of Finance and Economics, 49, p. 62-71.

Feigenbaum. A. V. (1991). Total Quality Control. 4th ed, Mc Graw, Hill, Inc, USA.

Horngren, T. Charles Foster. G. \& Dater. S (2012). Cost Accounting A Managerial Emphasis. 14th ed., Pearson Prentice Hall, USA.

Slack, Nigel; Chambers, Stuart \& Johnston, Robert (2010). Operations Management, Printice Hall, USA.

Trehan, Rajeev; Garg, Rajiv K. \& sachdeva, Anish (2014). Cost of Quality- A System Dynamics Approach, International Journal of Engineering Sciences, (3), p. 230 - 237. 